\section{HEIDEGGER E LEIBNIZ: A ABERTURA DO CONCEITO DE \\ MÔNADA}

Cristiano Bonneau*

Resumo: Este texto trata da reflexão heideggeriana sobre o conceito de mônada em Leibniz e suas determinações. Os apontamentos de Heidegger sobre o ser a partir do pensamento leibniziano promovem uma abertura fundamental da mônada, trazendo entre outras conseqüências, o perspectivismo e a idéia do ente enquanto pulsão. A limitação ontológica da mônada e sua capacidade de movimentar-se a partir de si mesma resultam em uma noção de representação e delineiam os contornos do ente. Esta discussão intenta demonstrar as possibilidades de compreensão do conceito de mônada partindo das reflexões de Heidegger sobre $A$ determinação do Ser do Ente segundo Leibniz.

Palavras-chave: Heidegger. Leibniz. Mônada.

A mônada leibniziana aparece numa reflexão de Heidegger de 1928, onde ele se propõe a discutir na filosofia de Leibniz, o tema referente ao ser. A questão cara e essencial da metafísica surge no texto heideggeriano como um diálogo com o filósofo alemão do século dezessete, colocando como escopo de investigação geral a Mônada. Mas, por que Heidegger parte da Mônada para discutir o tema mais central, difícil e denso da metafísica? Qual é o propósito de invocar a monadologia para buscar novas luzes sobre a questão que, de tão ampla e geral, traz para si todas as dificuldades de escolher um método que ao mesmo tempo esclareça e não deforme o objeto de análise, considerando que “(...) nós não nos relacionamos apenas com o ente, somos ao mesmo tempo, nós mesmos ente.” (Heidegger 1, p.221). O "Ser" é o conceito "mais universal" (Idem, p.28), é indefinível (Idem, p.29), e ao mesmo tempo, é o conceito evidente por si mesmo (Idem

* Mestre em Filosofia - UFPB-PB e Professor Assistente de Ciências Sociais da Universidade Federal da Parába. Este texto teve sua apresentação na Jornada "Recepção pela contemporaneidade do pensamento do século XVII", em 26 e 27 de maio de 2009, na USP, promovido pelo Grupo de Estudos Espinosanos. ibidem). Nas primeiras páginas de Ser e Tempo o problema sobre a questão e o sentido do ser aparecem, bem como os desafios de angariar um método capaz de pelo menos, apreender a própria questão.

Estas dificuldades de análise, apreensão e compreensão dos fenômenos e seus fundamentos, desvelam-se no paradoxo em que surge o ser que: aparecendo se esconde; esclarecendo se obscurece; e compreendido se torna indeterminado. "Nós nos relacionamos com o ente, a ele nos reduzimos, nele nos perdemos, por ele somos dominados e possuídos." (Heidegger 1, p.221). Neste ambiente de demonstração de um problema da filosofia, Heidegger mostra como Leibniz pensava a questão do ser, quais os limites dos entes descritos e a forma de organização da compreensão leibniziana sobre o problema.

Heidegger esclarece: “O que Leibniz entende por mônada engloba como que em si todos os significados gregos fundamentais: a essência da substância consiste no fato de que ela é mônada". (Heidegger 1, p.217). Este argumento revela que uma pesquisa pelo ente na sua substancialidade e unidade ontológica tem em Leibniz toda a herança da reflexão filosófica grega sobre a questão da essência e natureza das coisas. Assim Heidegger comenta que “(...) mônada é o elemento unificador simplesmente originário que previamente individualiza e separa." (Heidegger 1, p.217). Ou seja, corresponde ao cerne que deve ser investigado, tendo em vista que o desenvolvimento do pensamento leibniziano tem em grande medida seu substrato neste termo. Leibniz fundamenta desta forma, o conceito de Mônada para credenciá-lo como capaz de demonstrar aquilo que o ser é, garantir sua unicidade (princípio de identidade dos indiscerníveis) e seu lugar no cosmos, tendo em vista a identidade e a diferença dos pontos substanciais que compõem o mundo. A mônada “(...) é apenas uma substância simples que entra nos compostos. Simples, quer dizer: sem partes." (Leibniz 3, §2). 
Esta atribuição à Mônada está na sua própria capacidade de apresentar-se como alternativa a uma explicação puramente atômica dos elementos que compõem o mundo, declarando os entes deste como pontos metafísicos. Neste aspecto, o ser assume perspectivas para além de sua materialidade composta e desdobra-se em especulações possíveis por esta nova percepção dos entes. O que compõe o ser de Leibniz- a Mônada- e o fundamenta na existência, não se resume a um modo empírico, mas vai para além da pura condição apresentada pelas limitações da matéria e da percepção. A Mônada aparece investida de uma riqueza conceitual digna de ser investigada e lançando novas luzes para a compreensão dos seres. Podemos pensar neste elemento componente da mônada que pode ser explicado pela física, mas não se encerra nela; tem condições de ser situado pela matemática, que também não basta para determinar a essência dos seres. O elemento aqui determinado é a noção de força. Esta aparece como fator exponencial, conjuntivo e ordenador dos seres que se movem num movimento de dentro para fora, pela natureza hermética de sua natureza. Este limite interno de cada ser que age à partir de sua condição substancial é o que traça o seu movimento e atualiza constantemente a sua essência.

"Do que dissemos conclui-se que as mudanças naturais das Mônadas procedem de um princípio interno, pois em seu intimo não poderá influir causa alguma externa." (Leibniz 3, §11). Heidegger acentua a noção de força no interior da Mônada e relata a transição fundamental da substância que antes se manifestava como potentia activa e agora fundamenta-se como vis activa. A diferença entre estes dois termos aponta para a própria perspectiva leibniziana da Mônada- esta não é o ser em potência, mas corresponde na única possibilidade do ser. O ser é, na substancialidade de sua substância possibilidade. Não encerra-se somente como a possibilidade de ser, mas, sobretudo como o próprio ser da possibilidade. As conseqüências desta mudança apontam para a capacidade da Mônada leibniziana em conformar-se como um autômato, não apenas material, mas espiritual.

"Poder-se-iam denominar enteléquias todas as substâncias simples ou Mônadas criadas, pois contêm em si uma certa perfeição (ékhousi tò entelés), e têm uma suficiência (autárqueia) a torná-las fontes de suas ações internas e, por assim dizer, Autômatos incorpóreos." (Leibniz 3, §18)

A este movimento interno do ser que garante suas características fundamentais, o assegurando ontologicamente e existencialmente, Heidegger aponta como pulsão. A definição desta noção enquanto força ergue-se naquilo "que leva a ação à si mesmo, a partir de si mesmo e isto, na verdade, não ocasionalmente, mas por natureza." (Heidegger 1, p.219). A força deste termo apontado por Heidegger reflete-se no termo alemão Drang que corresponde a impulso, ímpeto, desejo, ânsia, necessidade, tendência. Enuncia-se pulsão enquanto capacidade interna e natural do ser, que existindo se manifesta enquanto ele mesmo, a partir de suas determinações internas na afirmação de sua identidade e sua existência. O fechamento da Mônada e sua essência em um puro possível revelam uma abertura no ser, não para o mundo, mas para ele mesmo. Daí podemos inferir, que, estando a Mônada no mundo, quando ela afirma a si mesma, no mesmo instante afirma a própria totalidade, ou seja, o mundo.

Ela se torna a única condição de possibilidade, mesmo em seu hermetismo fundamental, do mundo se abrir. Eis a abertura do conceito de Mônada. A reflexão de Heidegger parte para a questão sobre o fundamento da Mônada enquanto essência mesma do ente e da substância que o compõe. Esta questão lança-se em torna do elemento unificador da substância, capaz de manter sua capacidade existencial de fazer-se parte da totalidade, e compor as essências individuais dos entes? Para além da pulsão, 
Heidegger esclarece que o elemento MOI, o ego ou o eu é aquele que tem a potencialidade de promover esta síntese, que por sua vez corresponde à forma como o Dasein lança-se para mundo enquanto transcendência do ser-aí ek-stático.

Leibniz não tematiza em profundidade a natureza unificadora da Mônada. A partir de suas reflexões sobre o tema, é possível haurir das proposições do texto leibniziano, determinadas conseqüências. A percepção dos entes do mundo torna-se um movimento possível pela capacidade da Mônada em perceber a unidade nos compostos, que por sua vez, é formado pela própria unidade. A mudança de relação entre as unidades é acompanhada pela capacidade apetitiva da alma que marca as mudanças de estados nas relações entre os compostos, percebendo sua alteração. A morte, por exemplo, é a manifestação de outros arranjos entre as composições de unidades que formavam os indivíduos, tendo em vista que, o corpo, não estando mais em seu estado individual de corpo, torna-se parte em outros compostos que continuam expressando-se em sua natureza interna própria. O que não permanece nos compostos sucumbe e deixa de existir. A imersão na universalidade aparece nesta capacidade contínua das Mônadas em se tornarem entes, e arrumarem-se entre si, sempre em relação a uma totalidade absoluta e numa ordem capaz de suportar o existir.

A questão da origem das Mônadas é atribuída a Deus, porém, Leibniz não justifica a Mônada, mas, tão somente a descreve, como que, explicando sua composição, seus atributos e sua forma de manifestar-se, pela sua essência, na existência. Se foi um plano divino o ato da criação, certamente para Leibniz, fora o melhor plano possível. Assim, é na finitude da Mônada em que esta será fundamentada. Nem sua origem, nem seu destino pós existentia, mas o que lhe compõe enquanto ser no mundo e atrelado a capacidade de preencher as condições de se manter como um ente possível e existente
"Se antes pusemos de lado a conexão com a criação, isto ocorreu porque no caso se trata apenas como uma explicação dogmática. O sentido metafísico, entretanto, que na caracterização da mônada como criada é expresso, é a finitude." (Heidegger 1, p.227).

Neste sentido, Heidegger demarca na filosofia leibniziana o terreno de atuação das Mônadas, como a própria existência dos entes. A especulação permanece sobre aquilo que a Mônada enquanto 'pulsão' pode, exprimindose no espaço de fluxo e refluxo no qual a liberdade e sobretudo a noção de possibilidade podem ser pensadas. A Mônada tem uma expressividade universal, porém, presa às suas condições particulares de atuação. Essa condicionalidade é o reflexo da essência do ser que enquanto ente, torna-se capaz de refletir o mundo a partir de si mesmo. Esta expressão é a única possível, dentro dos limites naturais da condição monádica. A Mônada é o ser que representa de uma forma viva a totalidade, fazendo parte desta, mas por sua vez, incapaz de hauri-la em sua plenitude.

Somente sua condição finita, limitada e possível lhe dá uma idéia do todo, que se fragmenta de forma inevitável pela condição ontológica constituinte dos seres. O fechamento substancial da Mônada, sua capacidade de expressão do infinito pela sua finitude ontológica e o lançarse de maneira viva para o mundo, o colocam em condição de perspectiva do universo. É o indivíduo que compartilha o mesmo mundo, porém com impressões capazes de expressarem-se, mas impotentes no tocante a um compartilhamento efetivo entre as partes. Isto não quer dizer que não haja uma harmonia entre os arranjos. Os indivíduos só podem se dar enquanto tal, mediante a sua capacidade plena de organizar-se em suas partes. Esta ordem respeitada acarreta inevitavelmente na existência.

Cada parte experimenta o mundo à sua maneira, permanecendo 
isolada e solitária nesta ação inevitável enquanto capazes de se manterem viventes no mundo. A unidade não é senão, uma capacidade plena de apreender algum aspecto da totalidade de forma ordenada, por vezes distinta e não confusa. Este aspecto da unidade e da ordem, Leibniz compreende como enteléquias. A apercepção desta capacidade das enteléquias ele nomeia como razão. O cerne que compõem o indivíduo e o torna apto para a existência lhe dá acesso ao cosmos somente enquanto possibilidade e perspectiva. Quanto mais abrangente for uma visão de mundo, maior será o número de perspectivas que esta teve a capacidade de adotar. A totalidade só pode ser representada nestas condições pela idéia de Deus, que nada mais é, do que a soma de todas as perspectivas possíveis em todos os tempos. A finitude da Mônada consiste em que ela, não podendo ser Deus, torna-se somente partícula do mundo. O cosmos nada mais é do que a pura expressão vivente e pulsante de suas partes. Desta forma, Heidegger esclarece que “(...) na medida em que unifica- isto é sua essência-, individua-se a Mônada. (...) unifica ela somente de acordo com sua possibilidade o universo que de antemão é representado." (Heidegger 1, p.227).

Heidegger salienta que para além da questão matemática, em resposta a quantidade de vida e pontos de vista, o aspecto da unicidade da pulsão e da expressividade da totalidade, desvelam as características ontológicas dos entes e suas qualidades individuais. A idéia de uma experiência única e da não repetição do tempo fundamenta uma forma qualitativa de compreender a Mônada. Se o ser não se repete, ele é a única possibilidade de, em sua existência, perceber, sentir, manifestar uma existência única, autêntica e inviolável. Sua coerência reflete seu ser e sua manifestação particular, suas qualidades. A alma significa uma possibilidade mesma do universo e um ponto de vista qualitativo neste. Heidegger esclarece esta questão quando define a alma não apenas como um atributo de determinadas mônadas, mas uma modificação destas mesmas, demonstrando que o arranjo entre os agregados podem acarretar desdobramentos imprevisíveis, porém possíveis. A alma representa um ponto de vista não apenas pela sua finitude, mas pela sua capacidade de expressividade enquanto alma. É o reflexo da totalidade e da vida, representante do ser.

"Re-presentar não deve ser tomado aqui como faculdade particular da alma, mas sob o ponto de vista ontológico estrutural. Em conseqüência disso, a mônada não é alma em sua essência metafísica, mas dá-se o contrário: alma é uma possível modificação da Mônada. A pulsão não é um acontecer que ocasionalmente também representa; ela é por natureza representadora. A estrutura do próprio acontecer pulsivo se caracteriza pelo abrir dimensões, é ekstática." (Heidegger 1, p.225)

A mônada se apresenta como pura possibilidade, capaz de dar conta da infinidade de arranjos que compõem os indivíduos no mundo. Quando o ser da mônada se agrega e coloca-se em estado de composição, o ente aparece e mantém-se fundamentado por este pequeno universo que acaba de constituí-lo. A criação dos agregados se dá na mesma medida de sua existência e de sua expressividade do universal. Sua perspectiva inexorável e imanente apontam para seus limites, mas também suas possibilidades. A lógica da existência obedece a ordem de composição dos agregados e aquilo que, enquanto existentes tiveram a possibilidade de manifestar. Leibniz declara que: “(...) como todo o estado presente de uma substância simples é uma continuação natural do seu estado passado, assim também o presente está prenhe do futuro." (Leibniz 3, §22). Desta forma, o filósofo alemão do século XVII tem na Monadologia uma ontologia fundamental para explicitar uma razão do mundo, uma fundamentação dos seres que o 
compõem e a defesa de uma identidade que expressa-se de forma única, tendo em vista a infinitude de possibilidades que tornam-se efetivas na existência dos seres. O ser é, enquanto um possível que viera e existir, a própria coexistência com a totalidade de todos os vir-a-ser que poderiam compô-lo. Reflete ao mesmo tempo, finito e infinito, possibilidade e impossibilidade, fechamento e abertura.

A noção da mônada enquanto pulsão e possibilidade delimitam conceitualmente suas atribuições, mas não determina em absoluto as ações capazes dos seres. Apontam para o interior da mônada, onde surge um cosmos, que por sua vez torna-se uma perspectiva e incapaz de ser apreendido em sua plenitude. É assim que a mônada se abre e fecha ao mesmo tempo, representando o ser em seus desdobramentos ontológicos, em sua lógica e sua capacidade de exprimir a totalidade. A Mônada significa um modelo exemplar que dá vazão a um ato descritivo do universo, mostrando originariamente, a incapacidade de apreendê-lo.

“A Monadologia quer elucidar o ser do ente. Por isso, é preciso adquirir, seja por que via for, uma idéia exemplar de ser. Ela foi encontrada ali, onde algo semelhante ao ser se manifesta imediatamente ao que questiona filosoficamente." (Heidegger 1, p.221).

\section{REFERÊNCIAS BIBLIOGRÁFICAS}

1. HEIDEGGER, Martin. A determinação do ser do ente segundo Leibniz. Coleção "Os Pensadores", Tradução e Notas de Ernildo Stein. São Paulo, Editora Abril cultural, 1979.pp.215-229. , Ser e Tempo. Tradução de Márcia de Sá Cavalcante, $3^{\mathrm{a}}$ Ed., Editora Vozes, Petrópolis, 1997.p .325.

3. LEIBNIZ, Gottfried Wilhelm. A Monadologia. Tradução de Luís João Baraúna, Editora Nova Cultural Ltda, Coleção Os pensadores, 2000. p. 61-73.

\section{Heidegger and Leibniz- the openness of the concept of monad}

Abstract: This paper handles the heideggerian reflection on the concept of monad in Leibniz and its determinations. The comments that Heidegger does about the being from the leibnizian thought promotes a fundamental openness of the monad, bringing with it, among other consequences, the perspectivism and the idea of the beings as pulsion. The monad's ontological limitation and its capacity to move from itself result in a notion of representation and delimitate the beings's contours. The aim of this discussion is to demonstrate the possibilities of comprehension of the conception of monad taking as starting point Heidegger's reflections in 'From the last Marburg lecture course'.

Keywords: Heidegger, Leibniz, Monad 